\title{
Identifying the most important skills for PhD students in Food Science and Technology: a comparison between industry and academic stakeholders
}

\author{
Chelo González-Martínez ${ }^{\mathrm{a}^{*}}$, Peter Ho ${ }^{\mathrm{b}}$, Luis Cunha ${ }^{\mathrm{c}}$, Oliver Schlüter ${ }^{\mathrm{d}}$, And \\ PaOla Pittia ${ }^{\mathrm{e}}$ \\ ${ }^{a}$ Food Technology Department, Universitat Politecnica de Valencia, Camino de vera s/n, 46022, Valencia, \\ Spain \\ ${ }^{\mathrm{b}}$ University of Leeds, Leeds, United Kingdom \\ ${ }^{c}$ REQUimTE/DGAOT, Faculdade de Ciências, Universidade do Porto, Porto, Portugal \\ ${ }^{\mathrm{d}}$ Leibniz-Institut für Agrartechnik, Postdam-Bornim, Germany \\ ${ }^{\text {e }}$ Facoltá di Bioscienze e Tecnologie Agroalimentari e Ambientali, Università degli Studi di Teramo, Italy \\ ${ }^{*}$ Corresponding author \\ cgonza@tal.upv.es \\ TEL: + 34963877000 \\ FAx: + 34963877635
}

Received: 18 July 2014; Published online: 18 October 2015

Invited paper from the $3^{\text {rd }}$ International ISEKI_Food Conference - ISEKI_Food 2014 - Bridging Training and Research for Industry and the Wider Community - Food Science and Technology Excellence for a Sustainable Bioeconomy

\begin{abstract}
Nowadays, there is an increasing need of new skills for PhD students to face the future labour market prospects. $\mathrm{PhD}$ graduates must have qualities attractive not only in academia but also outside, in both manufacture and service-oriented enterprises, in small innovative companies, and in the civil services and public administration, among others. To know what the needs of these future employees are, is of great importance to be able to improve their personal and academic formation. The aim of this work was, in the framework of the EC-funded ISEKI_Food 4 network, to evaluate the most desirable specific and soft skills that $\mathrm{PhD}$ students should acquire by the end of their doctoral studies. To this aim, several surveys were conducted and sent to the different stakeholders (academia and food industry partners) in order to collect the information needed. Results showed that competences related to research skills and techniques, research management, personal effectiveness and communication skills were considered to be the most valuable skills to be acquired by our $\mathrm{PhD}$ students to meet the future needs of the labour market. The importance of these skills was appreciated differently, depending on the stakeholder. To sum up, some recommendations to integrate such valuable skills into the curricula of the $\mathrm{PhD}$ student are given.
\end{abstract}

Keywords: Third cycle studies; Skills; Generic competences; Specific competences

\section{Introduction}

Currently, most European and non-European countries are facing changes in their doctoral pro- grams. These changes are partly driven by the new European guidelines and by the uncertain future which surrounds this career.

Doctoral studies has a particular place in the Eu- 
ropean Research Area and the European Higher Education Area. It rests on the practice of research, which makes it fundamentally different from the first and second cycles. The main outcome of doctoral education is the early stage researcher (ESR) and their contribution to society through knowledge, competences and skills learnt by undertaking research, as well as awareness and openness towards other disciplines. The outcome of their research must testify to the originality of the research and be suitable for dissemination within the scientific community. On the other hand, career support for doctoral candidates must take into account individual goals and motivations and acknowledge the wide range of careers for doctorate holders. While the doctoral candidate is responsible for their career choices given the situation on the labour market, it is the institution's responsibility to provide support structures for professional development. Offering training in transferable skills (including understanding the ethics of research) should be a priority for doctoral schools and programmes. Building ties to the other sectors contributes to bridging the communication gap with potential employers and recruiters (EUA, 2010).

In the light of this scenario, the role of the research/doctoral schools is underlined, the importance of innovative structures to meet the future challenges is highlighted and the development of interdisciplinary training and transferable skills are being promoted to meet the needs of the wider employment market.

Few studies are currently available about $\mathrm{PhD}$ competences or skills. Recently, the main $\mathrm{PhD}$ competences for Food Studies have been reviewed (González-Martinez et al., in press). In this study, in the framework of the European ISEKI_Food 3 project (2004-2007), a list of competences or learning outcomes (L.O) for a third cycle level related to Food studies was developed. The work was organized by taking into account seven groups of outcomes dealing with research activities (subject-specific) and with transferable or soft skills (generic competences). As a continuation of the work done in this past project, the Thematic Network ISEKI_Food 4 (2008-2014) carried out some activities to be able to contribute to the advancement and relevance of the doctoral studies in the Food Science and Tech- nology field.

The aim of this work is, in the framework of the EC-funded ISEKI_Food 4 network, to evaluate the most desirable specific and soft skills (linked to employability of doctoral graduates) that $\mathrm{PhD}$ students should acquire throughout their doctoral studies, by taking into account both the Academia and the Food employers' points of view. What is unique about the study discussed herein is that the particular opinions and impressions of employers and academic programs, represented through faculty, are included as sources of information.

\section{Materials and Methods}

To collect the information, a survey was defined by the ISEKI_Food 4 project working group focusing on "Third cycle studies and Technology Transfer" (WG5). Initial drafts of the survey were developed by assessment from the $\mathrm{PhD}$ working group members, composed by university representatives from Germany, Spain, Portugal, Italy and Israel. After several iterations and reviews, a final form of the survey was agreed on.

The survey was addressed to two different stakeholders: academia members and food industry sector. The content of the survey was divided into two areas: generic skills and specific skills, based on previous studies (González-Martínez, Silva, \& Costa, 2014). Generic (or soft) skills are related to several competences in the area of personal effectiveness, communication skills, networking and team working and career management; and specific skills relate to research skills and techniques, research environment and research management.

Respondents were asked their perceived importance on each skill. A total of 33 skills were evaluated (15 soft and 18 specific). A blank questionnaire with the items to be answered by academia and industry partners is provided in Table 2.

The questionnaires were submitted to the partners (official and associated) of the network from 13th March to December 2012. The survey addressed to the food industry sector was also translated into five additional languages (Span- 
ish, French, German, Italian and Portuguese) and sent to food employers and national industrial associations.

Raw data from the survey were collected in two periods. Participants were asked to respond to the question items in the questionnaire using a 10-point Likert-type scale; however, feedback from participants prompted the simplification of the scale down to 5 categories. The original data with the 10 category scale was subsequently converted into 5 categories so that both set of data could be combined. The final data set resulted in data from 184 participants. Missing data were found in some cases; however, these participants were not removed.

Statistics analyses were carried out by ANOVA with $95 \%$ significance level using Statgraphics ${ }^{\circledR}$ Plus 5.1. Rasch analysis was conducted using the rating scale model using Winsteps (Linacre, 2014).

Table 1: Participant members

\begin{tabular}{ccc}
\hline Respondent & Academia & Industry \\
\hline UE members* & 67 & \\
Associated partners** $^{*}$ & 17 & 2 \\
TOTAL & 84 & 100 \\
\hline
\end{tabular}

* except: Denmark, Estonia, Finland, Luxemburg, Malta and Sweden

** Associated partners: South Africa, Thailand, Russia, Peru, Mexico, Ecuador, Israel , Canada, Brazil, Argentina, USA, Norway, Morocco, Turkey, Ukraine, Iceland

\section{Results and Discussion}

The analysis of the results was carried out taking into account 184 responses from both Industry and Academic members from the different countries participating in the project, as can be seen in Table 1. Results are discussed below, taking into account the different stakeholders.

\section{Academia group}

Eighty four academia members responded to the survey, coming from faculties related to the Food Science and Technology field, obtained from 38 countries; 22 European and 16 non-European associated partners (Table 1). $45 \%$ or the survey respondent reported being mostly senior (45\%) full professors (60\%), working at the university for more than 14 years (63\%). A good gender balance between respondents was also achieved ( $54 \%$ female- $46 \%$ male).

\section{Food Industry group}

These results are based on 100 answers from Food Industry Professionals obtained from 20 countries; 14 European and 6 non-European associated partners (Table 1).

Survey respondents were $52 \%$ female with a higher degree $(58 \%)$ or with $\mathrm{PhD}$ level $(34 \%)$. Time spent in the current company was less than 9 years for most of them, with the companies mainly SMEs (64\%), from a wide range of food sectors. A good balance in gender between respondents was also achieved (52\% female- $48 \%$ male). $82 \%$ of these organizations conduct R\&D activities continuously $(75 \%)$ and only $57 \%$ of these companies have employees with a $\mathrm{PhD}$ degree. According to them, the main factor affecting $\mathrm{PhD}$ employability was the limited size of the company (31\%) (Figure 1).

Both groups of respondents (Academia and Industry) were asked to score different competences presented in Table 2 in order to know their level of importance. The results showed that all the competences were scored very highly (mean value 4.3 ), thus indicating the positive perception of both stakeholders regarding these competences. These results also put in evidence the extremely high expectations we have for our doctorate holders, as no skills were rated low.

\subsection{Rasch analysis for each group without the removal of bias items}

In the preliminary Rasch analysis with all items present in the rating scale model, question items Q5 and Q23 had DIF contrast values of -1.07 and 0.67 logits respectively. A Mantel-Haenszel test also found Q5 (p-value of 0.0157) and Q23 (p-value of 0.0131) to be significant. Question items with DIF contrasts $>|0.64|$ indicates that

\begin{tabular}{l|l|l|l} 
IJFS | October 2015 | Volume 4 & pages 163-172
\end{tabular} 
166 | González-Martínez et al.

Table 2: List of the different skills evaluated in the survey

\section{GENERIC COMPETENCES}

\section{Personal effectiveness}

1.1 To demonstrate flexibility and open-mindedness, when working with different environments and people 1.2 To show ability to handle difficulties in research or other professional activities in an appropriate way 1.3 To show ability to react quickly and effectively to unpredictable/unforeseen situations

1.4 To show ability to adapt to different cultures and socio-economic environments (by means of an international experience, mobility)

\section{Communication skills}

2.1 To write (report) fluently and efficiently scientific publications

2.2 To defend own papers in scientific conferences 2.3 To show ability to communicate effectively to a broad framework of audiences (interdisciplinary teams, expert conferences, science for society, workshops)

2.4 To effectively support the learning of others when involved in teaching, mentoring or demonstrating activities 2.5 To communicate/discuss effectively with researchers from other disciplines

\section{Networking and team-working}

3.1 To develop and maintain co-operative networks and working relationships with supervisors, colleagues and peers within the institution and the wider research community 3.2 To understand one's behaviour and impact on others when working in and contributing to the success of formal and informal teams

3.3 To listen, give and receive feedback and respond perceptively to others

3.4 To develop capacity to engage in multidisciplinary works

\section{Career management}

4.1 To appreciate the need for and show commitment to continued professional development

4.2 To demonstrate an insight into the transferable nature of research skills to other work environments and the range of career opportunities within and outside academia

\section{SPECIFIC COMPETENCES}

\section{Research skills and techniques}

5.1 To demonstrate original, independent and creative thinking

5.2 To demonstrate ability to perform original and independent research within a scientific discipline or interdisciplinary collaboration

5.3 To demonstrate ability to "work in depth at the frontiers of knowledge' and across disciplinary boundaries 5.4 To formulate and apply solutions to research problems and effectively interpret research results

5.5 To demonstrate an understanding of relevant research methodologies and techniques and their appropriate application within one's research field

5.6 To analyze critically and evaluate one's findings and those of others

5.7 To recognize and integrate ideas and resources from a wide pool of sources

5.8 To demonstrate ability to work well across disciplines

\section{Research environment}

6.1 To show a broad understanding of the context in which research takes place: understand the relevance of research in society and the potential impact of research on individuals, groups and society

6.2 To demonstrate awareness of issues relating to the rights of other researchers and of research subjects e.g. confidentiality, attribution, copyright, ethics, malpractice, avoidance of plagiarism, ownership of data and the requirements of the Data Protection Act

6.3 To understand relevant health and safety issues and demonstrate responsible working practices

6.4 To understand the processes for funding, evaluation of research and grant application procedures

6.5 To understand different cultural environments, including the business world, and the contribution that knowledge transfer can make to society

\section{Research management}

7.1 To develop new research projects

7.2 To manage a team of people

7.3 To apply effective project management through the setting of research goals, intermediate milestones and prioritisation of activities

7.4 To recognize principles of project and time management 7.5 To apply for funding or attract other companies to work in a research project 


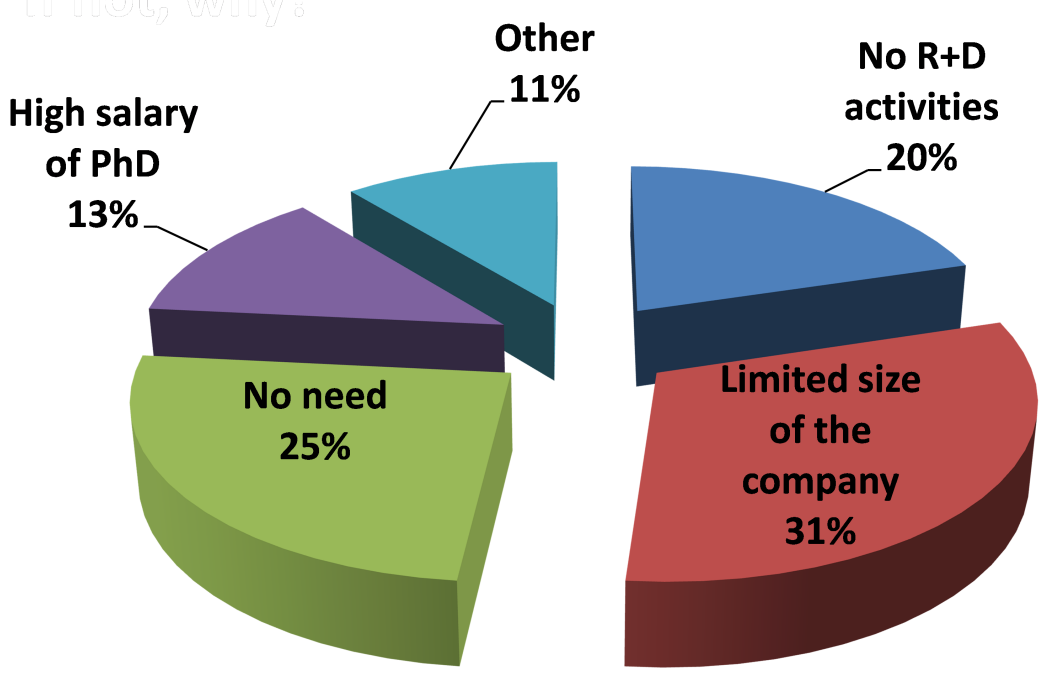

Figure 1: Main factors affecting $\mathrm{PhD}$ employability, according to Industry partners

these items might be biased against the type of stakeholder answering the question and as a result a direct comparison between the two groups (Industry and Academia) can only be compared after either (i) removing all items with DIF contrasts $>|0.64|$ before repeating the analysis with both groups in a single Rasch analysis; or (ii) calculating calibration (measures) of the non-DIF items and the steps for the rating scale (distance between each category on the scale) for all data and subsequent separate Rasch analysis for each group.

\subsection{Do industry and academia consider skills with the same degree of importance?}

Figure 2 shows the results of two Rasch analyses conducted separately for each group. The modified pathway plot can be used to indicate how well question items fit the Rasch model, by indicating which items have values of infit standardized $t$ statistic that is outside of -2 to 2 .

\begin{abstract}
Although, both infit and outfit standardized t statistic have been calculated in the Rasch analysis, the pathway plot shows only the infit values. Bond and Fox (2007) have indicated that the infit statistic is used as it "gives relatively more weight to the performances of persons closer to the item value" and that "persons whose ability is close to the item's difficulty should give a more sensitive insight into item's performance". Question items that are outside the acceptable infit range do not fit the criterion of unidimensionality and could indicate that these items are evaluated on another criterion other than "the degree to which the item is more likely to be chosen as an important skill". Including items with infit values higher than 2 is considered to give too haphazard a response pattern, due to large variations and can degrade the survey's measurement quality due to these items underfitting the model (Bond \& Fox, 2007).

The pathway plot, on the left of Figure 2 indicated that Q2 (2.2 logits) "To show ability to handle difficulties in research or other pro-
\end{abstract}



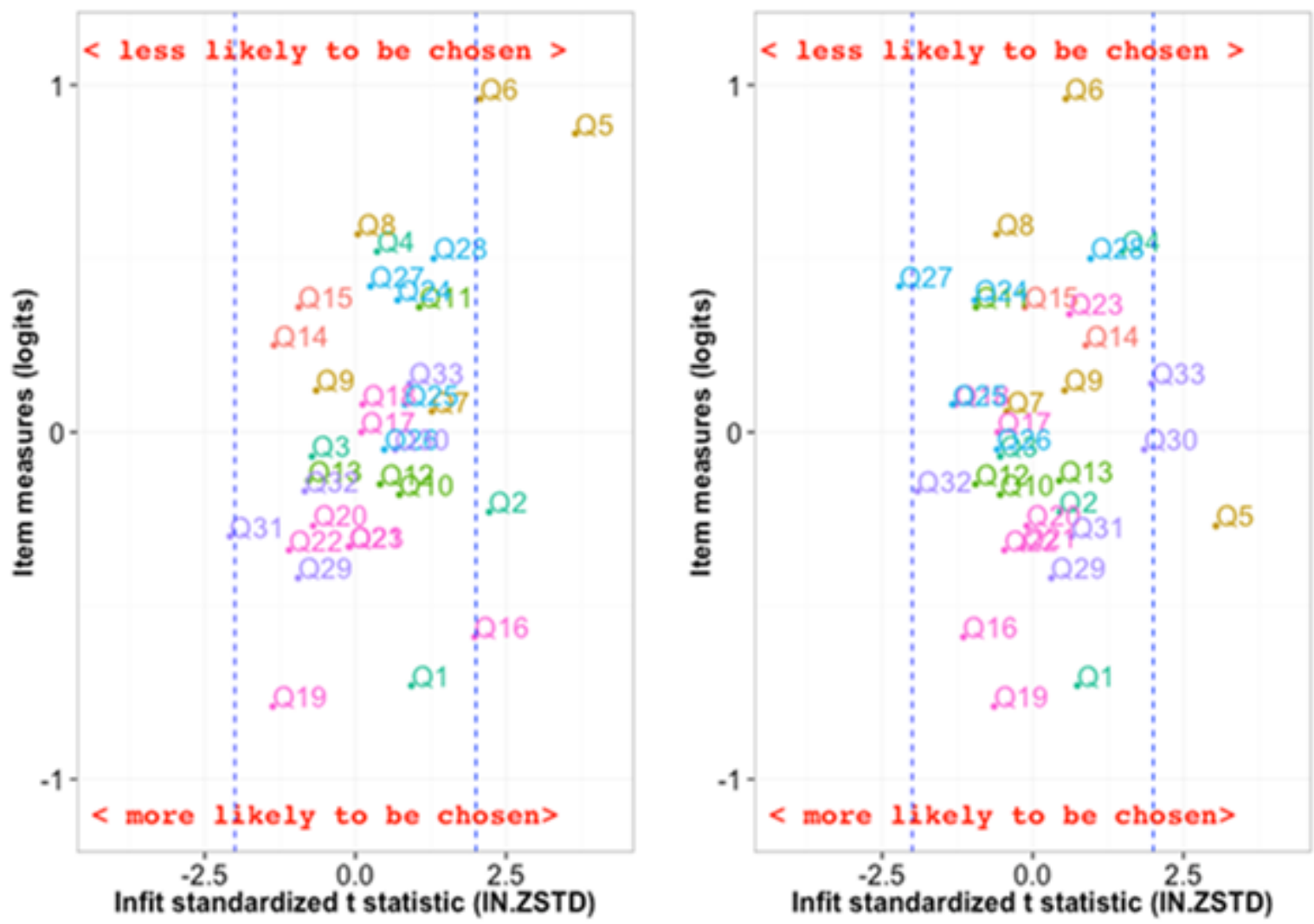

Figure 2: Pathway plots comparing Rasch measures for an analysis of all items for the Industry group (left) and the Academia group (right). Skills were classified into the following categories: Personal effectiveness (Q1-Q4); Communication skills (Q5-Q9); Networking and teamworking (Q10-Q13); Career management (Q14-Q15); Research skills and Techniques (Q16-Q23); Research environment (Q24-Q28); Research management (Q29-Q33). Blue dash line indicates the cut-off point of infit values for items outside the acceptable range of -2 to 2

fessional activities in an appropriate way", Q5 (3.7 logits) "To write (report) fluently and efficiently scientific publications", Q6 (2.1 logits) "To defend own papers in scientific conferences" and Q31(-2.1) "To apply effective project management through the setting of research goals, intermediate milestones and prioritisation of activities" were all outside the acceptable infit range for the industry group. Surprisingly, the academia group considered Q5 (3.0 logits) "To write (report) fluently and efficiently scientific publications" and Q27 (-2.2 logits) "To understand the processes for funding, evaluation of re- search and grant application procedures" in a different manner compared to other question items. Nonetheless, a clear pattern can be seen in Figure 2 with regard to which types of skills the survey participants considered to be more important than others which was for the most part the same for both groups. Career management skills (Q14, Q15) and communication skills (Q6 to Q9) was generally considered to be less important than Research skills and techniques (Q16 to Q22). Both groups considered Q6 "To defend own papers in scientific conferences" as the least likely to be chosen as an important skill, whereas 


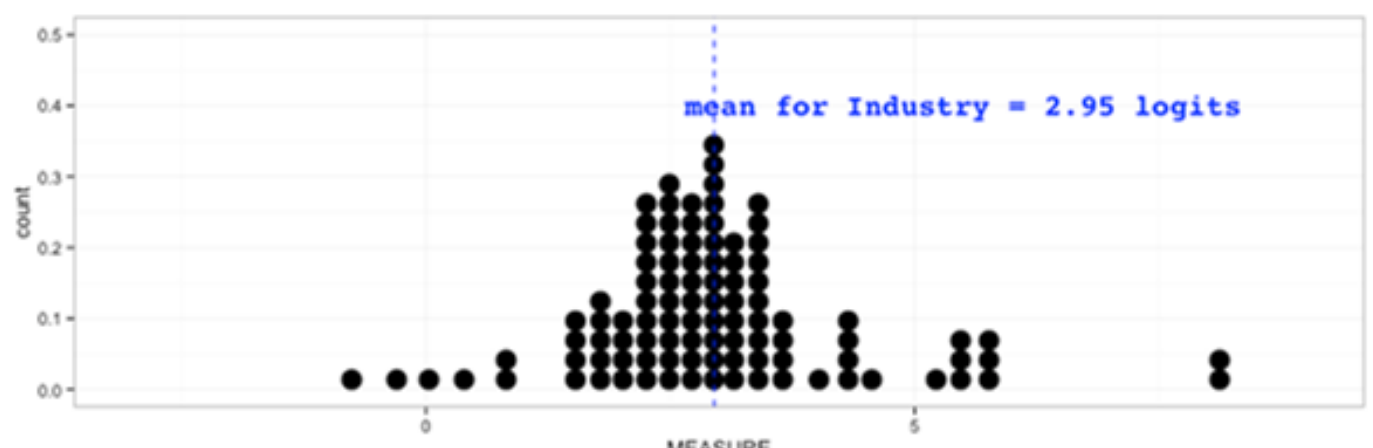

MEASURE

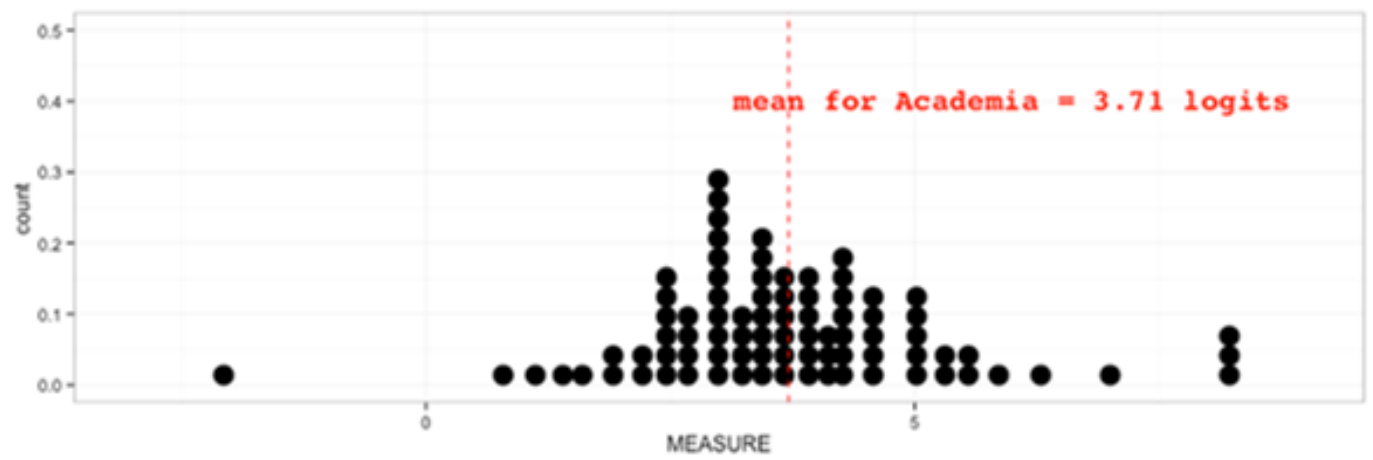

Figure 3: Dot plots of person measures between the groups from industry (top) and academia (bottom). Each dot represents one participant's Rasch measure in logits from answering all question items

the skills most likely to be chosen as important were Q19 "To formulate and apply solutions to research problems and effectively interpret research results" and Q1 "To demonstrate flexibility and open-mindedness, when working with different environments and people". However, while the group from industry considered Q5 "To write (report) fluently and efficiently scientific publications" as less likely to be chosen as an important skill and Q23 "To demonstrate ability to work well across disciplines" as more likely to be chosen as an important skill, the group from academia had the opposite response to these two skills.

Figure 3 shows the difference in the distribution of person measures between the two groups. The group from industry had a lower mean measure of 2.95 logits for measures that included non-extreme and extreme scores (a total of 100 participants), whereas the group from Academia had a higher mean measure of 3.71 logits for non-extreme and extreme scores (a total of 84 participants). There is a much wider spread of measures for the group in academia compared to Industry, indicating that there is more agreement within the group in industry compared to academia. However, the higher mean measure for academia indicates that they were more likely to agree that the set of competences were more important. This was confirmed by conducting an independent t-test between the person measures of the industrial group against academia, which indicated that the groups were significantly different $(\mathrm{p}$-value $<0.001)$. Table 3 shows that the item separation index and person reliability values were all in a range which indicated that the model fit was acceptable. 
Table 3: Summary statistics from Rasch analysis of participants from Industry and Academia

\begin{tabular}{lcccc}
\hline Type of Participant* & $\begin{array}{c}\text { Mean total } \\
\text { scores }\end{array}$ & $\begin{array}{c}\text { Mean } \\
\text { Measure }\end{array}$ & $\begin{array}{c}\text { Item separation } \\
\text { index }\end{array}$ & $\begin{array}{c}\text { Person } \\
\text { reliability }\end{array}$ \\
\hline Non-Extreme scores & & & & \\
Industry (98) & 119.0 & 1.63 & 3.55 & 0.93 \\
Academia (81) & 127.0 & 2.23 & 3.39 & 0.92 \\
\hline Both Extreme and & & & & \\
non-extreme scores & & & & \\
Industry (100) & 119.6 & 1.73 & 3.22 & 0.91 \\
Academia (84) & 127.8 & 2.40 & 2.90 & 0.90 \\
\hline
\end{tabular}

Table 4: Top three generic competences according to Academia and Industry responses

GENERIC COMPETENCES PERSONAL EFFECTIVENESS
$\%$ of responses

ACADEMIA INDUSTRY

1.1. To demonstrate flexibility and open-mindedness, when working with different environments and people 1.2. To show ability to handle difficulties in research or other professional activities in an appropriate way 1.3 To show ability to react quickly and effectively to unpredictable/unforeseen situations
$7 \% \quad 12 \%$

$7 \% \quad 12 \%$

$5 \%$

$11 \%$

ACADEMIA INDUSTRY

2.1. To write (report) fluently and efficiently scientific publications 2.3. To show ability to communicate effectively to a broad $6 \%$ framework of audiences (interdisciplinary teams, expert conferences, science for society, workshops)

\subsection{Top three most relevant competences}

Respondents were also asked to indicate out of the previous list, the top three most relevant generic competences and the top three most relevant specific competences at $\mathrm{PhD}$ level. Taking into account the results from Academia (Table 4), the most important generic competence was related to the categories of personal effectiveness and communication: To demonstrate flexibility and open-mindedness, when working with different environments and people, identified $15 \%$ of the time, followed by To write (report) flu- ently and efficiently scientific publications and To show ability to handle difficulties in research or other professional activities in an appropriate way at $13 \%$ and $11 \%$, respectively.

With regard to the specific ones (Table 5), those related to research skills and techniques was the most chosen: To demonstrate original, independent and creative thinking (15\%), followed by To formulate and apply solutions to research problems and effectively interpret research results, at $13 \%$ and To develop new research projects, at $10 \%$.

Regarding the Industry group, the top three most relevant generic competences were again 
Table 5: Top three specific competences according to Academia and Industry responses

\section{SPECIFIC COMPETENCES}

RESEARCH SKILLS AND TECHNIQUES

5.1 To demonstrate original, independent and creative thinking 5.4 To formulate and apply solutions to research problems and effectively interpret research results
$\%$ of responses

ACADEMIA INDUSTRY

$7 \% \quad 11 \%$

$9 \% \quad 9 \%$

ACADEMIA INDUSTRY

7.1 To develop new research projects

7.3 To apply effective project management through

$10 \%$

$-$

and prioritisation of activities

those related to the personal effectiveness and communication skills (Table 4). The most desired was To demonstrate flexibility and openmindedness, when working with different environments and people, identified $16.4 \%$ of the time, in agreement with Academia, followed by To show ability to react quickly and effectively to unpredictable/unforeseen situations and To show ability to communicate effectively to a broad framework of audiences (interdisciplinary teams, expert conferences, science for society, workshops) at $15 \%$ and $9.5 \%$, respectively.

With regard to the specific skills (Table 5), the most desired were To demonstrate original, independent and creative thinking and To apply effective project management through the setting of research goals, intermediate milestones and prioritisation of activities, both at $14.5 \%$, and To formulate and apply solutions to research problems and effectively interpret research results, at $12 \%$.

These results are in agreement with the scores given by both stakeholders when rating the different competences.

Taking into account the obtained results, some recommendations to integrate these skills into the curricula of $\mathrm{PhD}$ students can be provided, as follows:
- To enhance the mobility of students to different labs, countries;

- To promote the preparation and defense of the thesis by collection of research papers and critical reviews;

- To enhance the oral participation of students in national and international scientific conferences, workshops, seminars, etc;

- To promote the oral participation of students to a broad framework of audiences: public workshops, fairs, schools, television, radio... ;

- To involve them in the management procedures of current research projects and preparation and submissions of new proposals;

- To involve them actively in the coordination of master thesis projects or similar (final projects of undergraduate students).

\section{Conclusions}

Non-conventional structured programmes of activities are needed, ranging from advanced seminars and courses in research topics to training in transferable skills to face the changes in labour

IJFS | October 2015 | Volume 4 | pages 163-172 
market prospects of doctoral graduates and act as a 'quality label' in enhancing the career opportunities of $\mathrm{PhD}$ graduates.

Competences related to research skills and techniques, research management personal effectiveness and communication skills are considered to be the most valuable skills to be acquired by our $\mathrm{PhD}$ students to face the future needs of the labor market. The group from Academia was more likely to agree about the importance of the set of competences than the group from Industry.

The use of this data could help Universities to influence and structure the future training of doctoral students, surely not only in the Food Science and Technology field but also in other areas of interest. Also, it could be useful for the $\mathrm{PhD}$ students to realize that interdisciplinary educational profiles are needed to add value to their future professional development.

\section{References}

Bond, T. G. \& Fox, C. M. (2007). Applying the rasch model. Routledge, New York.

EUA. (2010). European University Association. Salzburg II Recommendations. European Universities' Achievements since 2005 in Implementing the Salzburg Principles.

González-Martínez, C., Silva, C. L. M., \& Costa, R. (2014). Phd competences of food studies. International Journal of Food Studies, 3(2), 136-144. doi:10.7455/ijfs/3.2.2014.a1

Linacre, J. (2014). Winsteps (version 3.75.1) [software]. Retrieved from http://www . winesteps.com/index.html 